\title{
Photostability and toxicity of finasteride, diclofenac and naproxen under simulating sunlight exposure: evaluation of the toxicity trend and of the packaging photoprotection
}

\author{
Maria Pia Sammartino*, Mauro Castrucci, Daniele Ruiu, Giovanni Visco and Luigi Campanella
}

\begin{abstract}
Background: Drugs photostability plays two different opposite roles; a real advantage arises considering the longer expiration time of the drugs while the consequent persistence in the environment involves an obvious negative effect bound to their harmfulness.

On this basis we tested the photostability and toxicity of three pharmaceutical active principles: Finasteride, Diclofenac and Naproxen. The pure active principles, as well as commercial drugs containing them, were considered; for the last, the protective effect of the packaging was also evaluated. Samples were irradiated according to the ICH Guidelines for photostability testing (The International Conference on Harmonisation of Technical Requirements for Registration of Pharmaceuticals for Human Use); a simulating sunlight source (a mercury-vapor lamp coupled to a tungsten filament one) was used to cover the wavelength range 300-2000 nm; Temperature, Relative Humidity, Irradiance and Illuminance were maintained constant during the photodegradation. The concentrations of the pharmaceutical active principles during the photodegradation were monitored by HPLC with UVNis detector. Toxicity tests were performed by means of an amperometric biosensor based on suspended yeast cells. Since the products obtained by the photodegradation process can result as toxic or more toxic than the original molecules, tests were performed first and after the photodegadation.
\end{abstract}

Results: After 90 hours of exposure the concentration resulted lowered by $42.9 \%, 88.4 \%$ and $91 \%$ for Finasteride, Naproxen and Diclofenac respectively. Toxicity of the pure active principles follows the same order of the photostability. After photodegradation a contribute of the reaction products was evidenced.

Conclusions: The simple and cheap analytical procedure here proposed, allowed to obtain not only data on photostability and toxicity of the pure active principles but, even if roughly, also useful information on the reactions kinetic and toxicity of the photodegradation products.

Keywords: Photostability, Toxicity, Packaging, Finasteride, Diclofenac, Naproxen

\section{Background}

From several years it is well known [1] that many compounds, including drugs, are photoreactive. In the past, the topic received scarce attention due to the incorrect belief that the packaging could protect the active principle so avoiding its photodegradation [2]. This led to a limited knowledge of the phenomenon until relatively recent time.

\footnotetext{
* Correspondence: mariapia.sammartino@uniroma1.it

Chemistry Department, "La Sapienza" University, P.le Aldo Moro 5, Rome 00185, Italy
}

The European Pharmacopoeia [3] states that a drug must be opportunely protected from the exposure to the light in order to avoid a reduction of the active principle concentration with a consequent lost of efficiency. Photodegradation was then recognized as an important limiting factor of the shelf life of a drug that can be greatly influenced by its wrong storage and/or handling. Thus not only quality control laboratories, but also international organization (like WHO) [4] and pharmaceutical companies [5,6] are interested in the development of a valid protection to 
preserve active principles from possible degradation. Degradation products could be more toxic than the starting reagents causing side effects on humans and producing unknown biological effects and new risks for ecosystems.

With the introduction of ICH guidelines [7] for carrying out photostability tests on drugs, researchers have deepened studies on the topic and several drugs were individually examined $[8,9]$; on the contrary, comparative studies on different drugs are still scarce. Such comparison can allow to obtain a scale of stability/recalcitrance (environmental persistence) of similar or different pharmaceutical formulations useful for solving ecopharmacology problems [10] (studies of the interaction between the environmental compartments and drugs for human and animals, products for personal care, for hospital cleaning, disinfectants, antibacterials). Here, we present a research aiming to compare the photostability of three active principles chosen among the most consumed in Italy [11]: Naproxen [12,13], Diclofenac [14,15] and Finasteride [16] (Additional file 1: Figure S1). The first two are well-known anti-inflammatory active principles while the third one is an inhibitor of 5-alphareductase (it inhibits the reaction of testosterone to dihydrotestosterone) and it is commonly used for the treatment of prostatic hypertrophy and androgenetic alopecia. Photodegradation tests were carried out using an irradiation source simulating sunlight (see Experimental paragraph). The photodegradation products were not determined because of their possible large number; we preferred to correlate their formation during the degradation with the toxicity trend. Really such data can be more useful since they take into account synergic effect of both the residual drug and all the photodegradation products. The active principles were determined by HPLC using UV/Vis detection. Absorption spectra of the pure molecules (Additional file 1: Figure S2) were recorded in order to set the detector for the chromatographic analysis at the most suitable wavelength. Active principles were subjected to photodegradation as pure molecules (mostly dissolved in water), and as solid pharmaceutical forms; in the last case, they were exposed inside the marketind pack as well as inside and outside the immediate pack, in order to evaluate eventual differences in the protection ability. Kinetic parameters for the photodegradation reaction were determined for the pure molecules dissolved in aqueous solution. The Integral Toxicity Index (before and after their exposure to the simulated sunlight) was obtained by means of an amperometric biosensor [17] based on suspended yeast cells.

\section{Results and discussion}

The accuracy of the analytical procedure adopted for the three drugs was evaluated considering as "true value" the concentration of the active principle declared by the producers; good inaccuracy values resulted, i.e. below the legal limits set for the title printed on the package [18]. Data are reported in Table 1, where also the precision of the measures can be evaluated.

In order to study the photodegradation kinetic and to optimize the chromatographic parameters we started with the analyses of the pure active principles. The choice of the initial concentration has followed the criterion to fall inside the linearity range of both the spectrophotometric and HPLC methods. On this base about $10^{-3} \mathrm{~mol} / \mathrm{l}$ aqueous solution were used.

Figures 1, 2 and 3 show the chromatograms obtained for the solutions of the three pure active principles during the photodegradation.

The retention time of Finasteride (Figure 1) is $5^{\prime} 25^{\prime \prime}$. The chromatographic peak decreases enough slowly (about $50 \%$ at the end of the test) and no other detectable peaks at the fixed wavelength appear. This could means that the basic structure is destroyed during the photodegradation and the formed fragments, with absorption at different wavelength, are less recalcitrant so that they undergo photodegradation preferentially, compared to Finasteride.

In the case of Diclofenac (Figure 2), having a retention time of 6' $30^{\prime \prime}$, the chromatographic peak decreases enough quickly during the first 30 hours (about 60\%) and then the process slows reaching a photodegradation percentage of about $85 \%$. With a similar speed trend, peaks of the reaction products appear in the chromatogram at lower retention times (between 3 and 5 minutes). In particular the peak at $4^{\prime} 20^{\prime \prime}$ increases up to reach the maximum after 30 hours of degradation, and then remain constant up the end of the experiment. This could indicates that, after 30 hours, this product also undergoes degradation and concentration remains almost constant as a consequence of a similar speed of formation from Diclofenac and photodegradation. More, the appearance of peaks with absorption at the same wavelength can mean that the basic structure remains intact in the first phase of the process, in agreement with its aromatic nature.

In comparison with the previous two, Naproxen (retention time of $4^{\prime} 45^{\prime \prime}$ ) undergoes a very quick photodegradation (Figure 3); after 30 hours of irradiation its chromatographic peak becomes not detectable. A peak at retention time equal to $5^{\prime} 30^{\prime \prime}$ quickly increases reaching its maximum after 15 hours of irradiation and then just as quickly decreases indicating that also its photodegradation starts. Other smaller peaks appears between the $2^{\prime} 50^{\prime \prime}$ to 4' 35", also attributable to the formation of degradation products, they become significant after 20 hours and remained almost constant up the end of the test. The same considerations made for the Diclofenac may be valid for Naproxen, the largest number of peaks is consistent with its naphthalenic structure.

In Table 2 the retention times of the three active principles and of their photodegradation products are listed. 
Table 1 Inaccuracy evaluated for the analysis of the three drugs

\begin{tabular}{|c|c|c|c|c|}
\hline Drug (tablets) & Active principle & Declared concentration (mg) & Found concentration $(\mathrm{mg}) \pm \mathrm{SD}$ & Inaccuracy (\%) \\
\hline Voltaren 50 & Diclofenac sodium salt & 50 & $51.8 \pm 0.2$ & +3.6 \\
\hline Momendol 220 & Naproxen sodium salt & 220 & $225.5 \pm 3.4$ & +2.5 \\
\hline Prostide & Finasteride & 5 & $5.16 \pm 0.07$ & +3.2 \\
\hline
\end{tabular}

Data come from at least 3 measures.

Since we chosen to use a simple and cheap analytical method to follow the photodegradation trend, we are unable to recognize the reaction products and to fully understand the kinetic pattern; anyway, taking into account the formula structures, the noticeable differences in the chromatograms allow us to make some assumptions.

Figure 4, where average concentration values vs. exposure time are reported, shows that, for Finasteride and Diclofenac, the trend lines reveal a first order kinetic $\left(C_{t}=\right.$ $\left.\mathrm{C}_{0} \cdot \mathrm{e}^{-\mathrm{kt}}\right)$ during all the exposition time $\left(\mathrm{R}^{2}=0.9850\right.$ for Finasteride and $\mathrm{R}^{2}=0.9962$ for Diclofenac). The half-life time $\left(t_{1 / 2}=(\ln 2) / k\right)$ results to be 106.6 and 24.2 hours for Finasteride and for Diclofenac respectively.

Naproxen trend follows the same kinetic equations only during the first 30 hours of irradiation, probably, as above said, this must be ascribed to the simultaneous photodegradation of its degradation product. In the first part, the decay curve fits a first order equation with an enough good correlation coefficient $\left(R^{2}=0.9855\right)$; basing on it, the half-life time results equal to 10.0 hours.

Toxicity tests were carried out, first and after the photodegradation tests, using yeast cell and a Clark oxygen electrode (see Experimental paragraph).
Table 3 shows that, for the three pure principles, the initial toxicity follows the order Naproxen $=$ Diclofenac $>$ Finasteride while at the end of the tests the order results $\mathrm{D}>$ $\mathrm{F}>\mathrm{N}$ with a toxicity decrease in all the cases. The toxicity decreases can be better understood basing on Figure 5 where the percentage reduction of the toxicity indexes (ItR) are compared with the photodegradation percentages (PDE). The ItR follows the same trend of the PD but, really, the percentages toxicity reduction always results lower than the photodegradation percentage; this means that surely the photodegradation products are also toxic even if at a lower extent respect to the corresponding drugs.

Results of the photostability tests are summarized in Figure 6. It can be seen that the photostability order is Finasteride $>>$ Diclofenc $>$ Naproxen for both the pure active principles and drugs containing them. In the last case the difference between Diclofenac and Naproxen is significantly higher with respect to the pure active principles. As expected, their persistence in the environment is significantly lower in aqueous solutions. Surely this is due to a physical protective effect of excipients; as a fact, the single molecules of active principles results differently exposed depending on the different position inside the powder grains

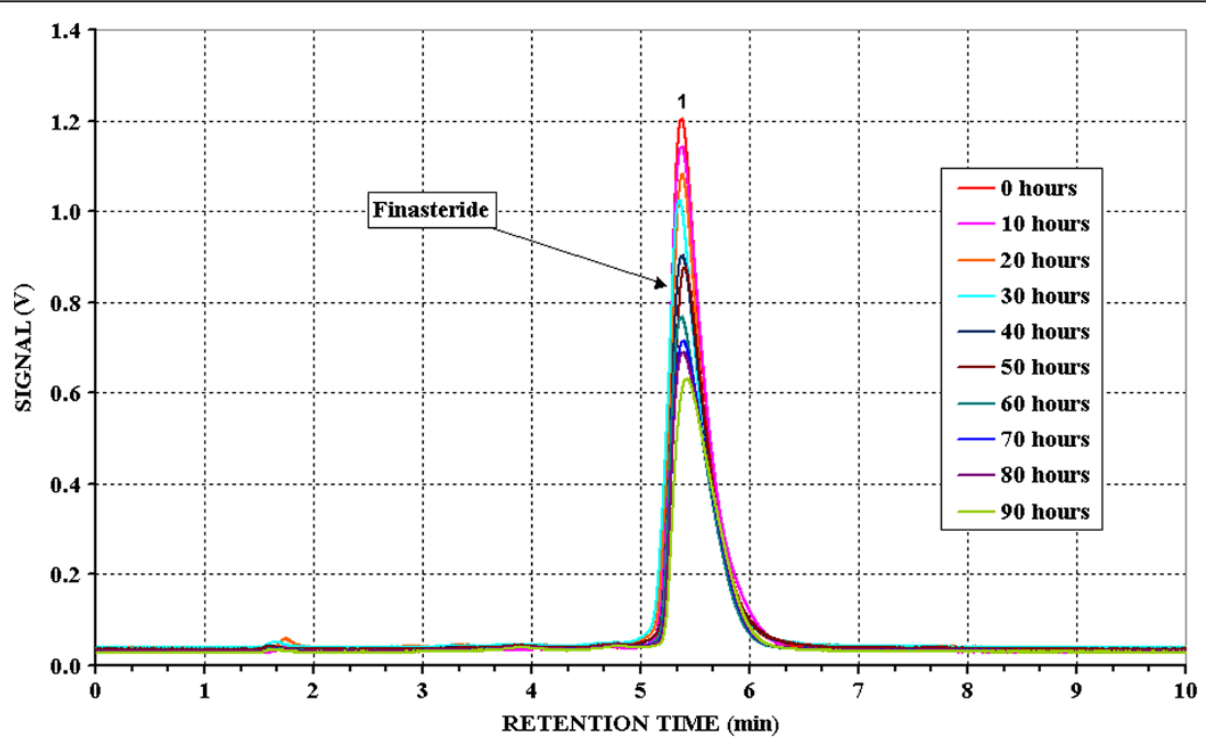

Figure 1 Chromatograms of Finasteride at different irradiation time. Initial concentration: $9.992 \cdot 10^{-4} \mathrm{~mol} / \mathrm{l}$ in 1:20 Acetonitrile/Water solution; eluent: Acetonitrile/Water 95:5; Alltech Alltima C8 $5 \mu \mathrm{m}, 250 \mathrm{~mm} \times 4 \mathrm{~mm} \varnothing$; flow: $1 \mathrm{ml} / \mathrm{min}$. 


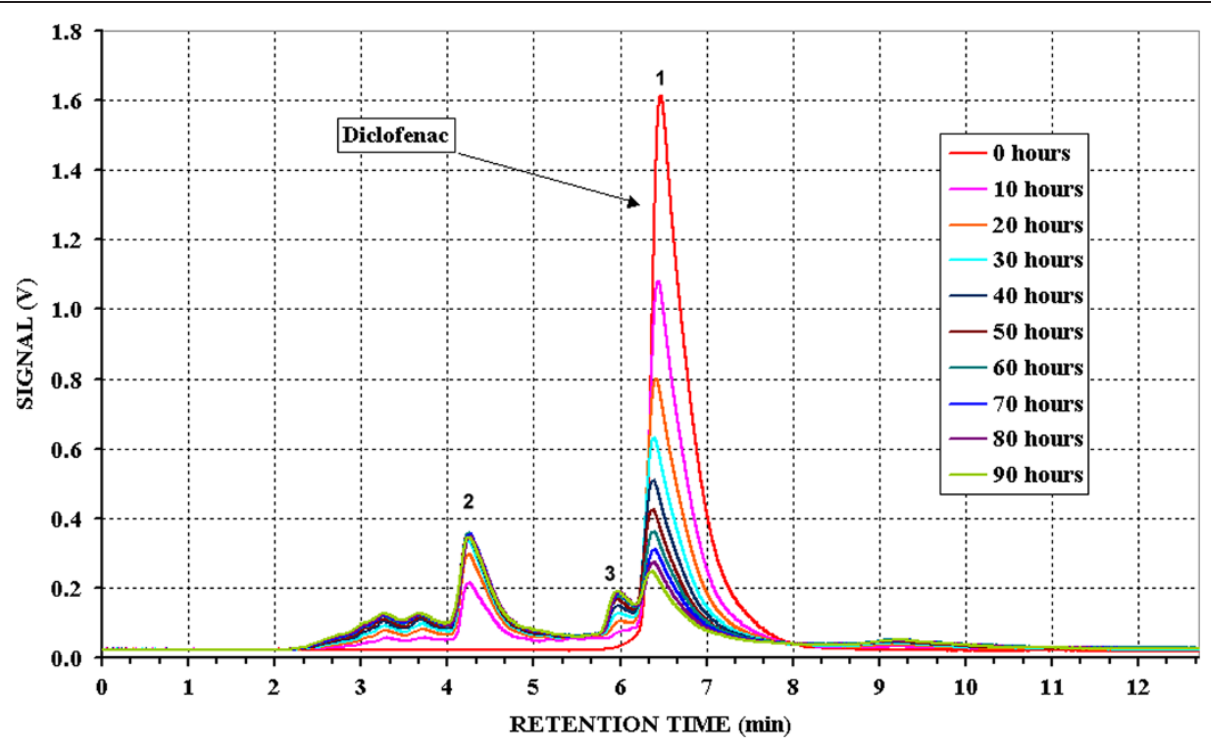

Figure 2 Chromatograms of Diclofenac at different irradiation time. Initial concentration: $3.003 \cdot 10^{-3} \mathrm{~mol} / \mathrm{l}$ in water; eluent: $\mathrm{pH} 3.3 \mathrm{phosphate}$ buffer/Acetonitrile/Methyl alcohol 30:35:35; Alltech Alltima C8 $5 \mu \mathrm{m}, 250 \mathrm{~mm} \times 4 \mathrm{~mm}$ Ø; flow: $1.25 \mathrm{ml} / \mathrm{min}$.

and powder layer (even if powders were stratified in a very thin layer as suggested by ICH guideline). Furthermore, other organic compounds contained in the drug can compete with the active principles during the photodegradation. For all the three drugs, the marketing package (cardboard) ensures a good protection against photodegradation while, as expected, the protective efficiency of the primary package is significantly lower. Since we chosen to follow the ICH guidelines, the differences in photostability between the drug naked and inside the primary packaging could be not significant due to the differences of exposed area and thickness.

\section{Experimental}

\section{Choice of the light source for the photodegradation}

Several measures of irradiance and radiant energy were performed on the terrace of the Chemistry Department of Rome "La Sapienza" University; some sunny days were randomly chosen in the months of May, June and July. Relying on these data and complying with ICH guidelines,

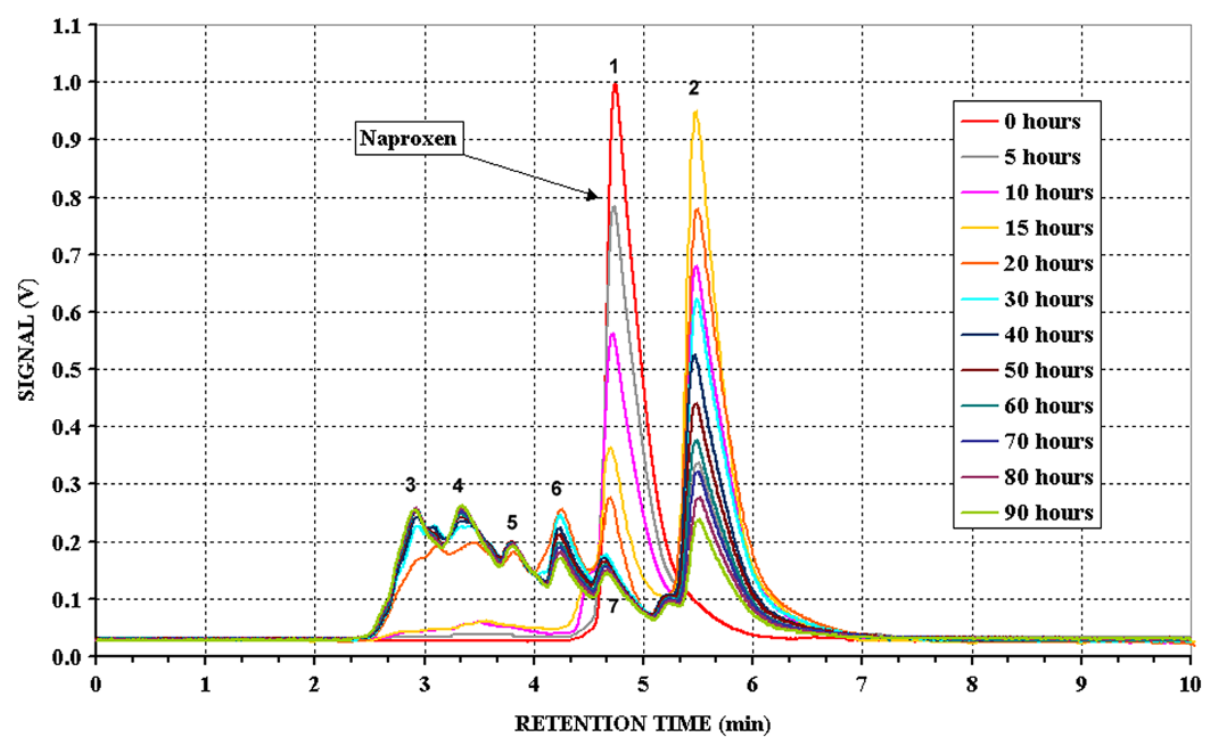

Figure 3 Chromatograms of Naproxen at different irradiation time. Initial concentration: $4.893 \cdot 10^{-3} \mathrm{~mol} / \mathrm{I}$ in water; eluent: $\mathrm{pH} 3.3 \mathrm{phosphate}$ buffer/Acetonitrile/Methyl alcohol 30:35:35; Alltech Alltima C8 $5 \mu \mathrm{m}, 250 \mathrm{~mm} \times 4 \mathrm{~mm} \varnothing$; flow: $1 \mathrm{ml} / \mathrm{min}$. 
Table 2 Retention time of the three active principles and their fragments coming from the photodegradation (see Figures 1, 2 and 3)

\begin{tabular}{lcc}
\hline Active principle & Peak & Retention time \\
\hline Finasteride & 1 & $5^{\prime} 25^{\prime \prime}$ \\
Diclofenac & 1 & $6^{\prime} 30^{\prime \prime}$ \\
Diclofenac fragment & 2 & $4^{\prime} 20^{\prime \prime}$ \\
Diclofenac fragment & 3 & $5^{\prime} 55^{\prime \prime}$ \\
Naproxen & 1 & $4^{\prime} 25^{\prime \prime}$ \\
Naproxen fragment & 2 & $5^{\prime} 30^{\prime \prime}$ \\
Naproxen fragment & 3 & $2^{\prime} 50^{\prime \prime}$ \\
Naproxen fragment & 4 & $3^{\prime} 20^{\prime \prime}$ \\
Naproxen fragment & 5 & $3^{\prime} 45^{\prime \prime}$ \\
Naproxen fragment & 6 & $4^{\prime} 15^{\prime \prime}$ \\
Naproxen fragment & 7 & $4^{\prime} 35^{\prime \prime}$ \\
\hline
\end{tabular}

we have chosen the source to be used for the photostability testing. To evaluate the radiant energy, a polycrystalline photovoltaic panel was connected in series to a $20 \mathrm{Ohm}$ resistance and to a data logger, the voltage was then monitored. The presence of the resistance was needed in order to have the highest possible value of sensitivity of the panel $-\delta \mathrm{V} / \delta\left(\mathrm{W} / \mathrm{m}^{2}\right)$. It corresponds to a high voltage variation by the slightest variation of radiant energy. A radiometer/luxmeter was placed near to the photovoltaic panel and irradiance $\left(\mathrm{W} / \mathrm{m}^{2}\right)$ and illuminance (lux) were measured at about 1 hour intervals from sunrise to sunset. Voltage values, measured at the same times by the photovoltaic panel, were plotted against irradiance measured by the radiometer/luxmeter; a straight line was obtained with a slope of $250 \pm 9 \mathrm{~W} \cdot \mathrm{m}^{-2} \cdot \mathrm{V}^{-1}$, an intercept of $6.23 \pm$
$0.06 \mathrm{~W} \cdot \mathrm{m}^{-2}$ and a good correlation coefficient $\left(\mathrm{R}^{2}=\right.$ 0.9959) (Additional file 1: Figure S3). So, a curve of irradiance was obtained from data collected by the data logger during 24 hours (Figure 7).

Using the PeakFit v4.12 software, the value $2.76 \cdot 10^{7} \mathrm{~J} / \mathrm{m}^{2}$ was obtained for the area below the curve. It corresponds to the solar energy collected by the photovoltaic panel over 24 hours of an average day (completely sunny) of July and results very close to the one declared on the website of the General Directorate of the European Commission Joint Research Centre $\left(2.71 \cdot 10^{7} \mathrm{~J} / \mathrm{m}^{2}\right)$ [19] for a completely July sunny day in Rome. Once established that collected data are significant, the next step was the choice of the irradiance to be used for the tests [20]. Basing on Figure 7, an energy equal to $600 \mathrm{~W} / \mathrm{m}^{2}$ was chosen that corresponds to the minimum irradiation during the sunniest hours. In such conditions, at least 22 hours of irradiation are needed in order to comply with ICH guidelines (exposure to not less than $1.210^{6}$ lux h and $200 \mathrm{~W} / \mathrm{h} / \mathrm{m}^{2}$ ).

Basing on what above said, in order to simulate at the best the solar spectrum, the OSRAM ULTRA-VITALUX [21] Sun Lamp was chosen for the photostability tests. The lamp consists of a tungsten filament (IR-Vis range) and a mercury-vapor lamp (UV range), (Additional file 1: Figure S4). The distance of the source from the sample was optimized in order to provide a value of $600 \mathrm{~W} / \mathrm{m}^{2}$ that was measured at each sampling time in order to control the lamp's stability. Eventual sample degradation, due to heating caused by the lamp, was minimized by means of a cooling system providing a laminar air flow. In such conditions, temperature and relative humidity, both monitored by a Lascar Mod. EL-USB 2 data logger, remained almost constant during the tests with values

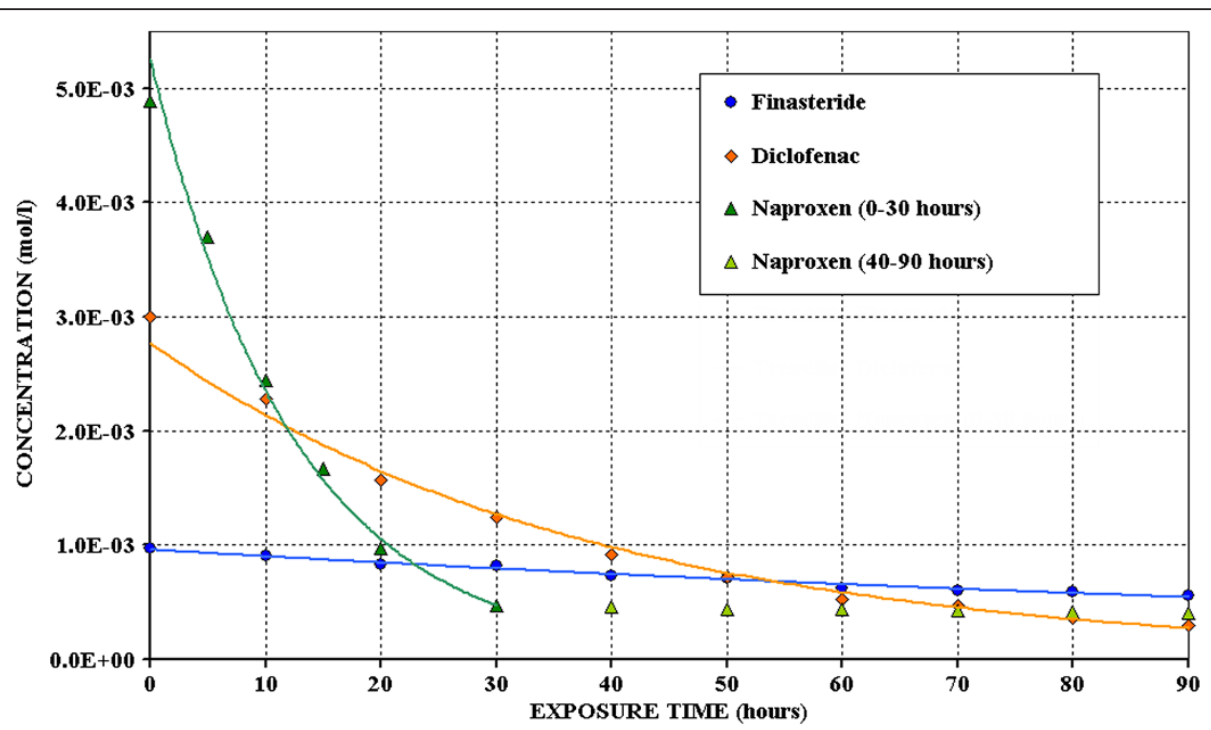

Figure 4 Trend of the Finasteride, Diclofenac and Naproxen concentrations during the photodegradation tests. 
Table 3 Integral toxicity index of active pure principles before and after exposure to $90 \mathrm{~h}$ of simulated sunlight

\begin{tabular}{lcccc}
\hline $\begin{array}{l}\text { Active } \\
\text { principle }\end{array}$ & $\begin{array}{c}\text { Photodegradation } \\
\text { time }(\mathbf{h})\end{array}$ & $\boldsymbol{\Delta} \mathrm{I}_{\mathbf{0}}$ & $\boldsymbol{\Delta}$ & $\mathbf{I}_{\mathbf{t}}=\mathbf{\Delta} \mathbf{l} / \mathbf{\Delta} \mathbf{I}_{\mathbf{0}}$ \\
\hline Finasteride & 0 & $3.26 \pm 0.02$ & $1.65 \pm 0.02$ & 0.51 \\
& 90 & $3.46 \pm 0.04$ & $1.35 \pm 0.03$ & 0.39 \\
Diclofenac & 0 & $3.45 \pm 0.02$ & $2.66 \pm 0.01$ & 0.77 \\
& 90 & $4.77 \pm 0.02$ & $2.25 \pm 0.02$ & 0.47 \\
Naproxen & 0 & $3.06 \pm 0.01$ & $2.35 \pm 0.02$ & 0.77 \\
& 90 & $4.06 \pm 0.03$ & $0.55 \pm 0.01$ & 0.14 \\
\hline
\end{tabular}

Values comes from at least 3 tests.

equal to $20 \pm 2^{\circ} \mathrm{C}$ and $42 \pm 2 \%$ respectively. Experimental conditions adopted for the photostability tests are reported in Additional file 1: Table S1 of the EDF.

\section{Integral toxicity test}

An already widely applied method [22,23] was used in order to determine the integral toxicity of both the considered active principles, and drugs containing them, first and after the photodegradation tests. The respiratory activity of Saccharomyces Cerevisiae suspended yeast cells was evaluated by a Clark oxygen sensor in presence and absence of the sample, an integral toxicity index was then calculated taking into account the difference.

Shortly, $250 \mathrm{mg}$ of yeast cells are suspended in $100 \mathrm{ml}$ of a $1 \mathrm{~mol} / \mathrm{l}$ glucose aqueous solution (yeast nutrient), for at least 2 hours, to optimize their respiratory activity. A Clark oxygen electrode is then immerged in $10 \mathrm{ml}$ of the previous solution in a thermostated at $25 \pm 1^{\circ} \mathrm{C}$ cell and maintained under magnetic stirring till the stabilization of the signal (usually between 7 and $8 \mathrm{ppm}$ ). $1 \mathrm{ml}$ of the sample solution is then added; a decrease of the respiratory function of the yeast, evidenced by an oxygen concentration

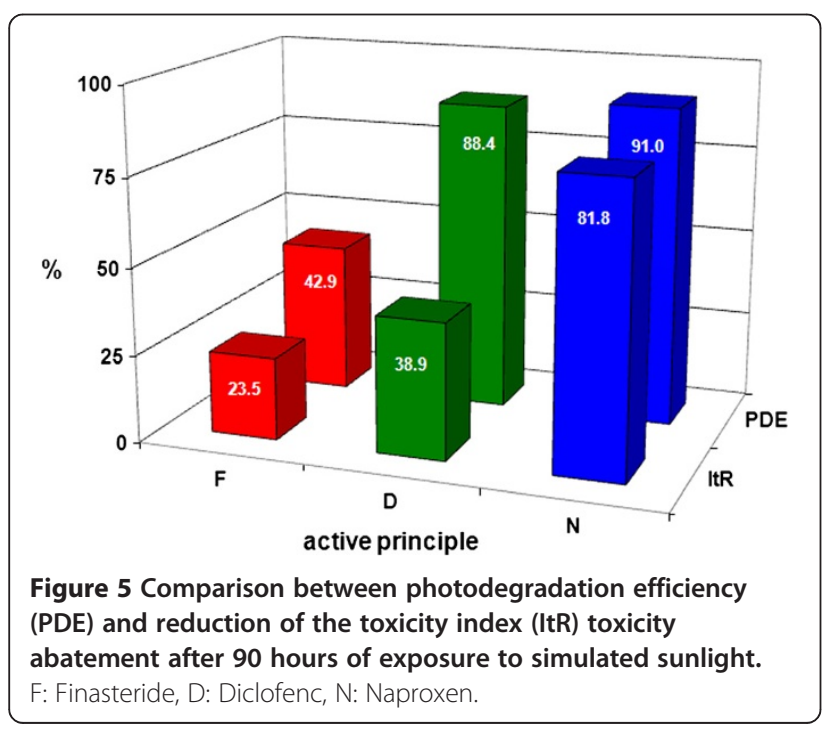

increase until a new steady-state, is observed that results proportional to the integral toxicity of the sample. The integral toxicity index is calculated as $\mathbf{I}_{\mathbf{t}}=\Delta \mathbf{I} / \Delta \mathbf{I}_{\mathbf{o}}$ (see Figure 8 ). $\Delta \mathbf{I}_{\mathbf{o}}$ is then due to the addition of the yeast so being proportional to both the total number of the yeast cells and their breathing activity while $\Delta \mathbf{I}$ is bound to the toxic activity of the sample (concentration and intrinsic toxicity) but also to the number and viability of yeast cells; so, the most accurate toxicity index results to be $\Delta \mathbf{I} / \Delta \mathbf{I}_{\mathbf{o}}$.

\section{Photodegradation process}

Photostability tests were initially carried out on aqueous solutions of the three pure active principles in order to speed up the process and to obtain kinetic information; furthermore, in such conditions we can also have a rough evaluation of their persistence in natural water bodies where they can enter (really at concentration of several order lower than those we here tested) [10]. Solutions were irradiated inside conical flasks of Pyrex England glass because its low absorption at wavelength higher than $320 \mathrm{~nm}$ (Additional file 1: Figure S5) complies with $\mathrm{ICH}$ guidelines for photostability testing. Irradiation was carried out for 90 hours and, at preset intervals, $0.5 \mathrm{ml}$ aliquots were sampled and stored in the dark until the analysis.

20 tablets of each drug were used for the photostability test: 5 tablets were not radiated in order to use them as reference (blank), while 5 tablets were exposed inside the marketing pack (cardboard box), 5 tablets were exposed inside the primary pack, 5 tablets were exposed by removing all packaging, after a fine grinding and thin layering on glass plate.

\section{Calculations for photostability and toxicity test}

The photodegradation efficiency (PDE) was calculated as follows

$$
\mathrm{PDE}=\frac{\mathrm{A}_{\mathrm{f}}}{\mathrm{A}_{\mathrm{i}}} \times 100
$$

where $A_{f}$ and $A_{i}$ are the final and initial areas of the chromatographic peaks registered for the active principle.

Likewise the toxicity reduction $\left(\mathrm{I}_{\mathrm{t}} \mathrm{R}\right)$ was calculated as follows

$$
\mathrm{I}_{\mathrm{t}} \mathrm{R}=\frac{\mathrm{I}_{\mathrm{tf}}}{\mathrm{I}_{\mathrm{ti}}} \times 100
$$

where $\mathrm{I}_{\mathrm{tf}}$ and $\mathrm{I}_{\mathrm{ti}}$ are the final and initial toxicity indexes, calculated as above said.

\section{Conclusions}

Even if simple and cheap, the proposed procedure can be a starting point to obtain useful information about the fate of drugs entering the environment as a consequence of the normal metabolic processes or bad wasting and so on; a 


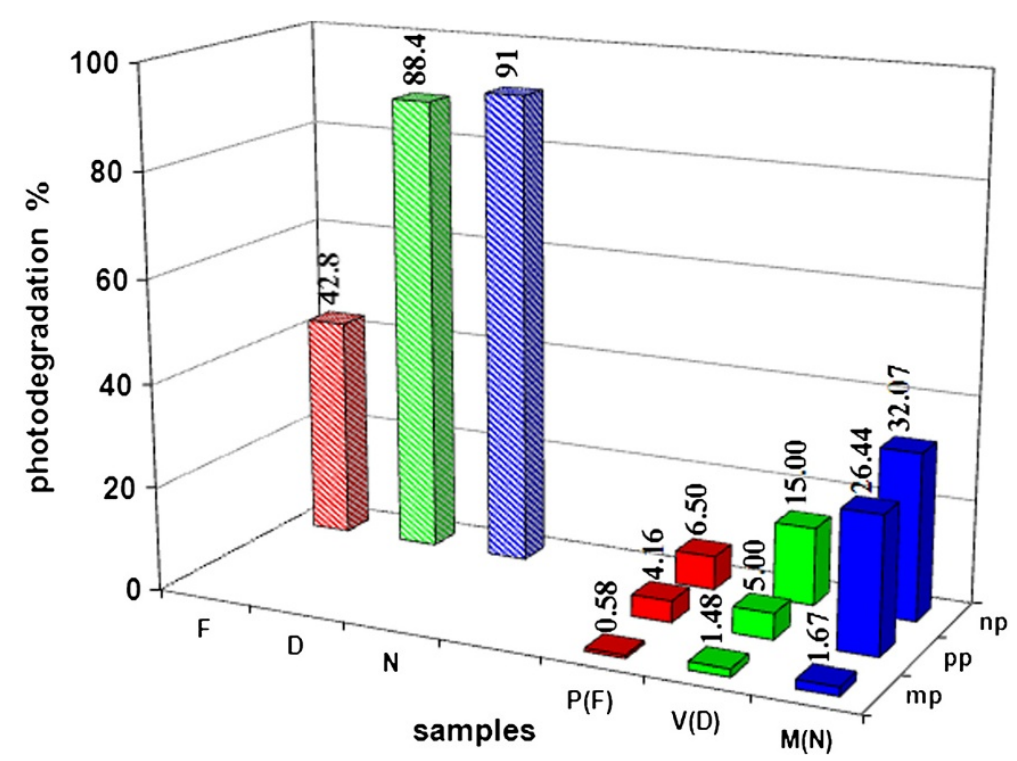

Figure 6 Photodegradation percentages obtained after $90 \mathrm{~h}$ irradiation for both pure active principles and drugs. F: Finasteride, D: Diclofenc, $\mathbf{N}$ : Naproxen, $\mathbf{P}(\mathbf{F})$ : Prostide (containing Finasteride), V(D): Voltaren (containing Diclofenac), $\mathbf{M}(\mathbf{N})$ : Momendol (containing Naproxen); mp: marketing package (cardboard), pp: primary package (plastic blister), np: no package (naked tablet). Data come from at least nine measures, i.e. three measures on each solution obtained from three tests; SD\% $\leq 2.5$.

more complex procedure (analyte enrichment) is needed to take into account the very low concentration up today found there [10]. On the contrary, the proposed procedure can be of help in optimizing the process conditions adopted in water treatment plants of pharmaceutical industries; in such case, the concentration is enough high and its decrease need to be speeded up using, as an example, heterogeneous photocatalysis through UV irradiation catalyzed by $\mathrm{TiO}_{2}$ that can be combined with visible and/or microwaves irradiation $[24,25]$. Also in these cases the coupling of the two analytical techniques, HPLC and toxicity tests, allows us to achieve the goal of obtaining data not only on the photostability but also on non-specific toxicity of the active ingredients and, though roughly, of the photodegradation products. A nonspecific toxicity test is surely more useful, at least for a first approach, than specific ones; in addition, the use of yeast cells respects ethical principles (no use of higher animals) and, especially, the toxic effects on these cells result very similar to those on human ones [26]. The three considered pure active

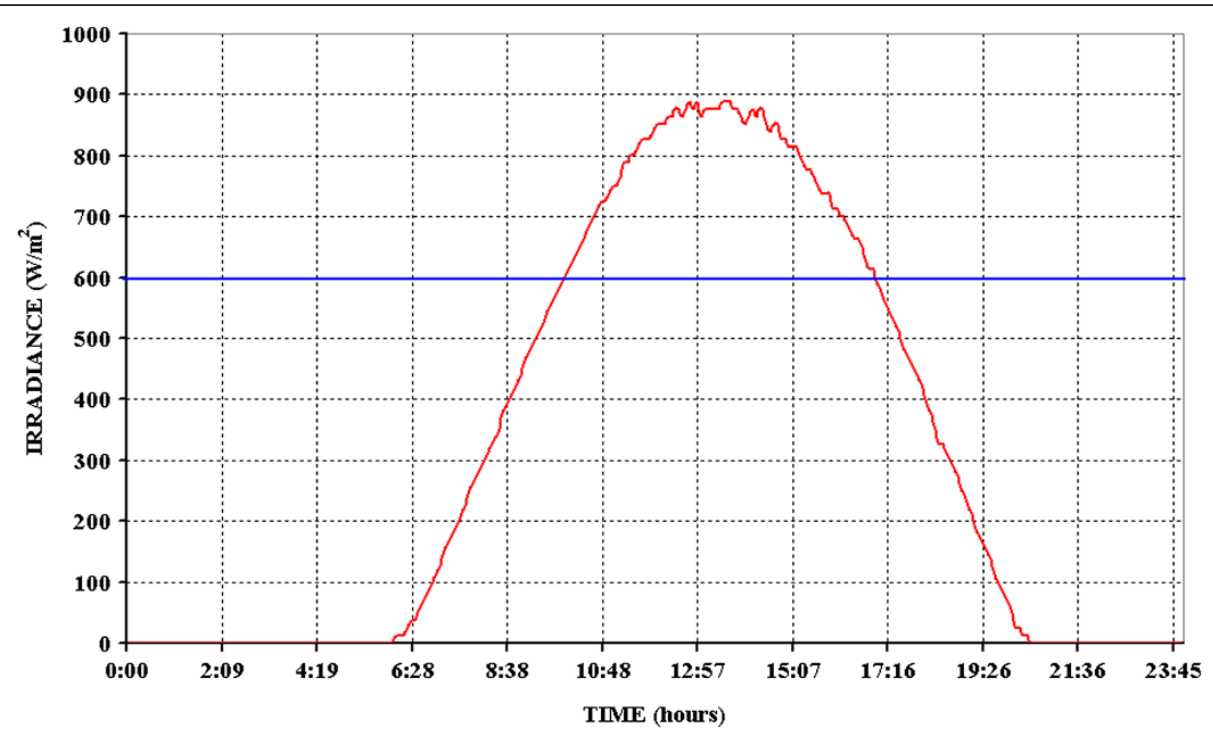

Figure 7 Average solar irradiance measured in Rome (Italy) during a day on July. 


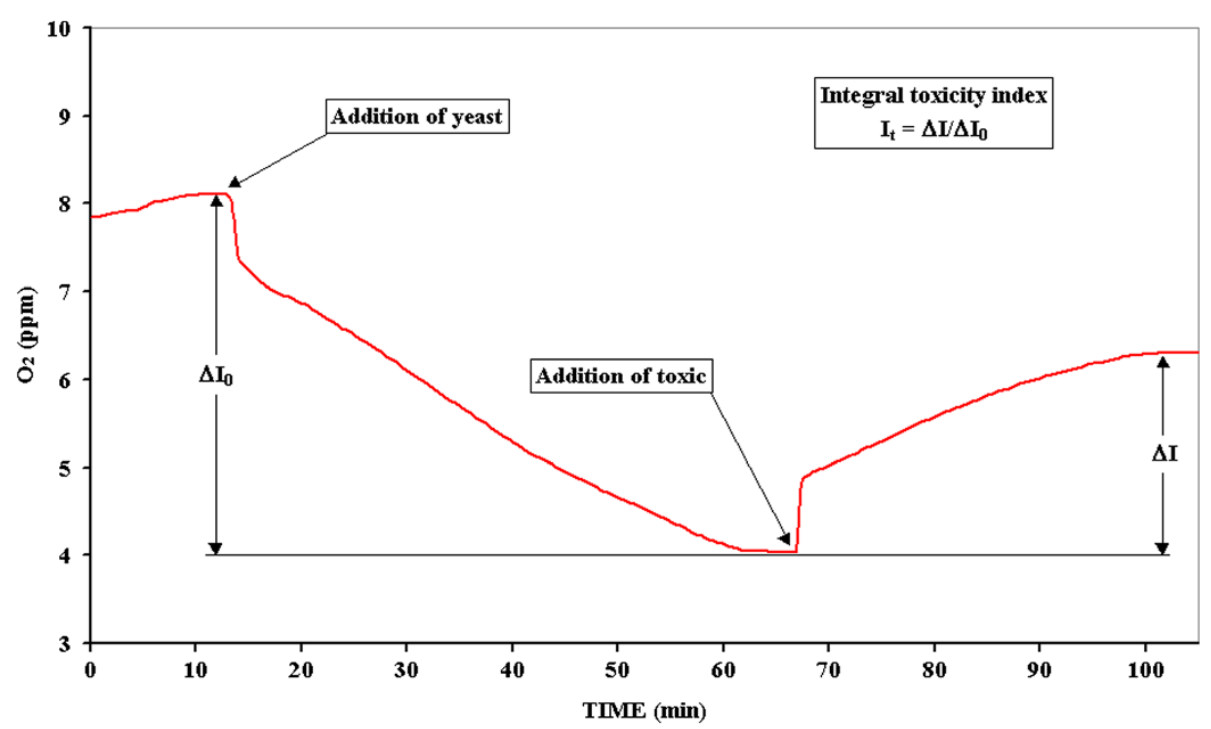

Figure 8 Trends of the oxygen concentration during the toxicity test.

principles, in aqueous solutions, undergo to an enough quick photodegradation with estimated half-life times equal to about 10, 30 and $100 \mathrm{~h}$ for Naproxen, Diclofenac and Finasteride respectively. Regarding the drugs, considered that following the ICH guidelines, we posed in extreme conditions, data reveal that the excipients exert a high protective effect against the degradation of the active principle. Surely the marketing package ensure an almost complete protection while, for tests performed on the drug inside the primary pack, we cannot separate the contribute of the excipients from that of the blister but, anyway, especially for Naproxen, photodegradation occurs at a significant level. Such data can be surely useful to establish the drug's "expiration date" but, as above said, our main goal was to also obtain toxicity data first and after photodegradation. The toxicity order for the three pure active principles results Diclofenac $=$ Naproxen $>$ Finasteride luckily inverse with respect to their photostability. For all the three considered drugs, the percentage toxicity reduction (ItR\%) after the photodegradation resulted, at different extent, lower than the photodegradation percentage (PD\%) so revealing a toxicity of the photodegradation products. In particular looking at the Figure 5, it could be stated that the toxicity of products coming from the photodegradation of Naproxen are less toxic than those from Finasteride that, in turn, are less toxic than those of Diclofenac but, really such order is not reliable since their different photostability surely plays a role in their toxicity.

What above said highlights the need for further research to obtain complete information, i.e., the use of more advanced analytical techniques, a more detailed time trend for the toxicity and so on.

Surely the topic is of great environmental interest because the drugs are pollutants that tend to increase in concentration, due to both the aging of the population and increase of industrial pollutants [27-29]. Their photostability plays an important role in contrasting their own pollution; as a fact, a low photostability let to a low environmental persistence but a complete toxicity abatement can be attained only after their mineralization [30]. In our tests, may be due to their not adequate irradiation time, the solar light resulted not completely suitable can be so useful in all the cases of unintentional leakage of drugs while inside water treatment plants the process is controlled and speeded up using, as an example, heterogeneous photocatalysis, by $\mathrm{TiO}_{2}$, combined with $\mathrm{UV}$ and micro-waves irradiation [24,25]. Also in these cases the proposed procedure can be of help in optimizing the process conditions.

\section{Methods}

\section{Chemicals and drugs}

Acetonitrile (99.9\%), water plus (distilled water filtered at $2 \mu \mathrm{m}$ ) and methyl alcohol (99.9\%), all of HPLC grade, monobasic potassium phosphate $(99.0 \%)$, orthophosphoric acid (98\%) from Carlo Erba Reagenti (Milan, Italy).

Finasteride (N-tert-Butyl-3-oxo-4-aza-5 $\alpha$-androst-1en-17 $\beta$-carboxamide; $\geq 98 \%$ ), Diclofenac Sodium Salt (2[(2,6-Dichlorophenyl)amino]benzeneacetic acid sodium salt; $\geq 98 \%)$, Naproxen Sodium Salt ((S)-6-Methoxy- $\alpha$ methyl-2-naphthaleneacetic acid sodium salt; $\geq 98 \%$ ) from Sigma-Aldrich (Milan, Italy).

Momendol 220 tablets containing $220 \mathrm{mg}$ of Naproxen Sodium Salt (Aziende Chimiche Riunite SpA Francesco Angelini, Italy), Prostide, tablets containing 5 mg of Finasteride (Sigma-Tau Industrie Farmaceutiche Riunite SpA, Italy) and Voltaren 50, tablets containing $50 \mathrm{mg}$ of 
Diclofenac Sodium Salt (Novartis Farma SpA, Italy) were purchased from several pharmacies in Rome, Italy.

All the three drugs are sold in cardboard boxes. The immediate pack of Prostide and Momendol consists of opaque white plastic, while the one of Voltaren consists of transparent colourless plastic. All tablets are covered by a polysaccharide film. The complete compositions are listed in Additional file 1: Table S2 of the EDF.

\section{Sample pre-treatment}

All pure active principles were weighed by means of an analytical balance $(0.01 \mathrm{mg}$ resolution) and solutions were prepared using glass flasks of Class A grade. Diclofenac and Naproxen were dissolved in ultrapure water, while for Finasteride a 1:20 $\mathrm{CH}_{3} \mathrm{CN} / \mathrm{H}_{2} \mathrm{O}$ mixture was used because not enough soluble in water.

Tablets of drugs were finely ground in a porcelain mortar and quantitatively racked in a centrifuge tube together with about $6 \mathrm{ml}$ of solvent; the centrifuge tubes were sonicated for 5 minutes and then centrifuged at $10,000 \mathrm{rpm}$ for 10 minutes in order to extract the active principle; supernatants collected from three successive extractions were brought to volume in a suitable flask and analysed by HPLC.

\section{Instruments}

The HPLC equipment consists of a Kontron pump mod. 422, with head pump mod. 420, a Rheodyne valve injection mod. 7125, a $20 \mu$ loop, a Kontron UV/VIS detector mod. 430 connected to a data logger (Pico Technology Mod. Dr. Daq), a PC equipped with the softwares PicoLog v5.16.2 and PeakFit v4.12. An Alltech reversed phase column (mod. Alltima C8 250 x 4.6 mm I.D.) filled with particles of $5 \mu \mathrm{m}$ of diameter was used as stationary phase while a mixture of Acetonitrile/Water 95:5 was used as eluent for Finasteride and a mixture of $\mathrm{pH} 3.3$ phosphate buffer/Acetonitrile/Methyl alcohol 30:35:35 for Diclofenac and Naproxen.

A Perkin-Elmer mod. Lambda 16 spectrophotometer was used to select the wavelength to be set for the HPLC detector.

Temperature was maintained at $25 \pm 1^{\circ} \mathrm{C}$ using a Alltech 330 Column Heater thermostatic bath in which the column was immersed.

A radiometer/luxmeter Gossen - model Mavolux Digital was used for the measures of irradiance, illuminance and radiant energy while temperature and humidity were monitored by a data logger Lascar - model EL-USB 3.

The equipment for the Toxicity test consists of a glass thermostated cell; a Clark oxygen electrode Orion 97-08 (Thermo Electron Corporation); an Orion Microprocessor Ionalyzer/901 potentiometer; an Amel Model 868 recorder. Saccharomyces cerevisie yeast cells were used as biological mediator.

\section{HPLC analysis}

The wavelength for the HPLC's UV detector was chosen basing on the UV/Vis absorption spectra of the pure active principles (Additional file 1: Figure S2): $205 \mathrm{~nm}$ for Finasteride, $275 \mathrm{~nm}$ for Diclofenac and $262 \mathrm{~nm}$ for Naproxen. Spectra were acquired in the suitable solvents i.e. the one used as mobile phases for the HPLC analyses. Calibration curves were built not only to follow the photodegradation, but also to test the linear range for each active principle; basing on their lower value, we choose the initial concentration of the pure active principles to be subjected to photodegradation; the criterion was that, after a $90 \%$ of photodegradation, the residual concentration had to be appreciated. Additional file 1: Table S3 of EDF summarizes the experimental condition adopted for the analysis as well as the main analytical parameters of the calibration curves obtained for the three active principles.

\section{Additional file}

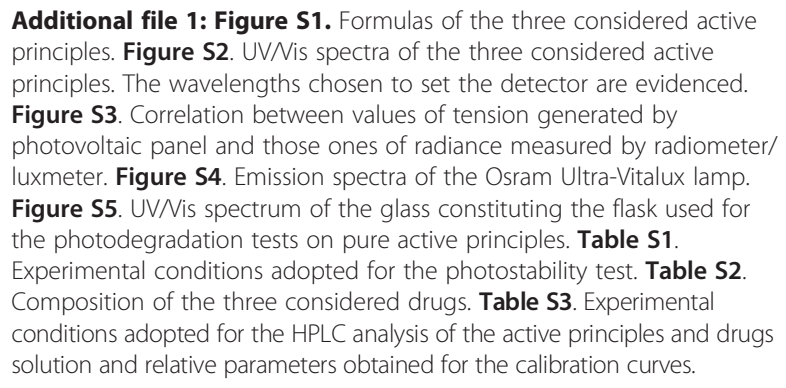

\section{Competing interests}

Each single author of this paper declares to not have any competing interests of some sort with brands and companies cited in the text. Further, authors are/were not employed in any of the cited company, they have not received fees for consulting or research funding from cited brands.

\section{Authors' contributions}

LC and GV conceived the research and followed its steps. DR carried out the experimental work and draw preliminary figures and tables summarizing the data; SMP supervised the processing of data checking their analytical consistency and the real utility to achieve the goal of the research. MC along with MPS have been involved in drafting the manuscript and revising it critically for important intellectual content. All authors have read and approved the final manuscript.

Received: 26 June 2013 Accepted: 17 November 2013

Published: 10 December 2013

\section{References}

1. Pasteur L: Transformation of the two tartaric acids into racemic acid. Discovery of inactive tartaric acid. New method of separating racemic acid into dextro- and laevo- tartaric acid. Comp Rend 1853, 37:110.

2. Albini A, Fasani E: Drugs Photochemistry and Photostability. Cambridge: The Royal Society of Chemistry; 1998. ISBN: 9780854047437.

3. European Directorate for the Quality of Medicines (EDQM): The European Pharmacopoeia. 6th edition. Strasbourg: BDC Ed.; 2008. ISBN: 9789287160546.

4. WHO: Pharmaceutical packaging - an overview including some considerations for paediatrics. http://apps.who.int/prequal/trainingresources/pq_pres/ workshop_China2010/english/22/003-PharmaceuticalPackaging.pdf.

5. Bhat J: Role of packaging material on Pharmaceutical product stability; 2009. http://www.ipapharma.org/events/stability/jbhat.pdf. 
6. Van Weeren $R$, Sashidharan $A$ : Determining drug Stability and selecting packaging. Pharmaceut Med Packaging News 2007, 15(9).

7. International Conference on Harmonisation of Technical Requirements for Registration of Pharmaceuticals for Human Use (ICH): Topic Q1B - Photostability testing of new active substances and medicinal products CPMP/ICH/279/95. In /CH Guidelines; 1996. http://www.ich.org/fileadmin/ Public_Web_Site/ICH_Products/Guidelines/Quality/Q1B/Step4/ Q1B_Guideline.pdf.

8. Tønnesen HH: Photostability of Drugs and Drug Formulations. 2nd edition. Boca Raton, Florida: CRC Press LLC; 2004. ISBN 0415303230.

9. Bajaj S, Singla D, Sakhuja N: Stability Testing of Pharmaceutical Products. J Appl Pharmaceut Sci 2012, 02(03):129-138.

10. Sammartino MP, Bellanti F, Castrucci M, Ruiu D, Visco G, Zoccarato T: Ecopharmacology: deliberated or casual dispersion of pharmaceutical principles, phytosanitary, personal health care and veterinary products in environment needs a multivariate analysis or expert systems for the control, the measure and the remediation. Microchem J 2008, 88(2):201-209.

11. OsMed (Osservatorio Nazionale sull'Impiego dei Medicinali): L'uso dei Farmaci in Italia - Rapporto Nazionale anno 2005 (the drugs consume in Italy - national relationship for year 2005). Rome: Tipografia Quattroventi Editor; 2006:83-89. ISBN 9788849001372.

12. Tixier C, Singer HP, Oellers S, Müller SR: Occurrence and fate of carbamazepine, clofibric acid, diclofenac, ibuprofen, ketoprofen, and naproxen in surface waters. Environ Sci Technol 2003, 37(6):1061-1068.

13. DellaGreca $M$, Brigante $M$, Isidori $M$, Nardelli A, Previtera L, Rubino $M$, Temussi F: Phototransformation and ecotoxicity of the drug NaproxenNa. Environ Chem Lett 2003, 1(4):237-241.

14. Eriksson J, Svanfelt J, Kronberg L: A photochemical study of diclofenac and its major transformation products. Photochem Photobiol 2010, 86(3):528-532

15. Salgado R, Pereira VJ, Carvalho G, Soeiro R, Gaffney V, Almeida C, Vale Cardoso V, Ferreira E, Benoliel MJ, Ternes TA, Oehmen A, Reis MA, Noronha JP: Photodegradation kinetics and transformation products of ketoprofen, diclofenac and atenolol in pure water and treated wastewater. J Hazard Mater 2013, 244-245:516-527.

16. Syed AA, Amshumali MK: LC determination of finasteride and its application to storage stability studies. J Pharm Biomed Anal 2001, 25(5-6):1015-1019.

17. Coulet PR, Blum LJ: Biosensor principles and applications. New York: Marcel Dekker Inc; 1991. ISBN 9780824785468.

18. Directive 2001/83/ec of the European Parliament and of the council of 6 November 2001 on the Community code relating to medicinal products for human use. http://www.emea.europa.eu/docs/en_GB/document_library/ Regulatory_and_procedural_guideline/2009/10/WC500004481.pdf.

19. Photovoltaic geographical information system of general directorate of the european commission - Joint Research Centre: http://re.jrc.ec.europa.eu/ pvgis/apps4/pvest.php.

20. Piechocki JT: Selecting the right source for pharmaceutical photostability testing. In Drugs: Photochemistry and Photostability. Edited by Albini A, Fasani E. Cambridge: The Royal Society of Chemistry; 1998:247-271. ISBN: 9780854047437.

21. Osram Website, Osram ULTRA-VITALUX sunlight lamp technical data sheet. http:// www.osram.ch/osram_ch/FR/Outils_et_Services/Documentation_a_telecharger/ Magazines_clients/Newsletter/TRADE_Newsletter/pdf/Decembre_2010/ 105S001GB_DB_Ultra_Vitalux_UV1.pdf.

22. Campanella L, Sammartino MP, Dragone R, Tromboni R: Test respirometrico e controllo dell'inquinamento. Inquinamento 2005, 73:64-67.

23. Campanella L, Favero G, Tomassetti M: Immobilised yeast cells biosensor for total toxicity testing. Sci Total Environ 1995, 171(1-3):227-234.

24. Campanella L, Cresti R, Sammartino MP, Visco G: Microwave assisted photodegradation of pollutants. In Proc. SPIE 3534, Environmental Monitoring and Remediation Technologies (Boston, MA, 1998). Boston: The International Society for Optical Engineering; 1999:105-113.

25. Visco G, Bellanti F, Castrucci M, Costanza C, Campanella L: Heterogeneous photocatalysis degradation of wasted drugs in water matrix by combined UV/ Vis/Microwave. Bologna-Rimini, Italy: X EuCheMS-DCE International Conference on Chemistry and the Environment; 2005:4-7.

26. Dragone R, Frazzoli C, Grappelli C, Campanella L: A new respirometric endpoint-based biosensor to assess the relative toxicity of chemicals on immobilized human cells. Ecotox Environ Safe 2009, 72(1):273-279.
27. Zuccato E, Calamari $D$, Natangelo M, Fanelli R: Presence of therapeutic drugs in the environment. Lancet 2000, 355(9217):1789-1790.

28. Ternes TA: Occurrence of drugs in german sewage treatment plants and rivers. Water Res 1998, 32(11):3245-3260.

29. Hignite C, Azarnoff DL: Drugs and drug metabolites as environmental contaminants: Chlorophenoxyisobutyrate and salicylic acid in sewage water effluent. Life Sci 1997, 20(2):337-341.

30. Rittmann BE: Definition, objectives, and evaluation of natural attenuation. Biodegradation 2004, 15(6):349-357.

doi:10.1186/1752-153X-7-181

Cite this article as: Sammartino et al:: Photostability and toxicity of finasteride, diclofenac and naproxen under simulating sunlight exposure: evaluation of the toxicity trend and of the packaging photoprotection. Chemistry Central Journal 2013 7:181.

Publish with ChemistryCentral and every
scientist can read your work free of charge
"Open access provides opportunities to our
colleagues in other parts of the globe, by allowing
anyone to view the content free of charge."
W. Jeffery Hurst, The Hershey Company.
- available free of charge to the entire scientific community
- peer reviewed and published immediately upon acceptance
- cited in PubMed and archived on PubMed Central
- yours - you keep the copyright
submit your manuscript here:
http://www.chemistrycentral.com/manuscript/

